\section{The first purely ceramic-based universal restorative}

VOCO presented several proven and innovative products at the BDIA Dental Showcase 2015 such as Admira Fusion, the worldwide first purely ceramic-based universal restorative material. Silicon oxide forms the chemical base for this new nanohybrid ORMOCER restorative material, not only for the fillers but also for the resin matrix. This offers several remarkable advantages: Admira Fusion, in comparison with all restorative composites of market relevance, shows by far the lowest level of polymerisation shrinkage ( $1.25 \%$ by volume) and extremely low shrinkage stress.

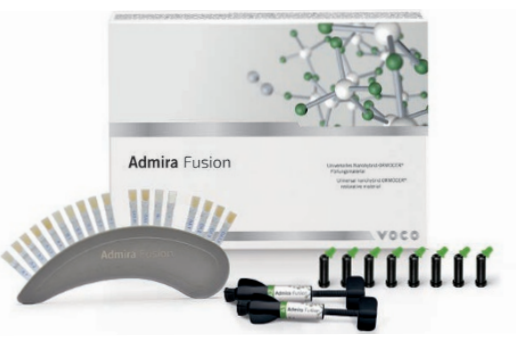

The ORMOCERs used in the manufacture of Admira Fusion make it highly biocompatible, as there is no content of classic monomers. Admira Fusion has an $84 \%$ (by weight) content of inorganic fillers and covers a broad spectrum of indications. Admira Fusion's particularly high colour stability gives it an additional edge. This very homogeneous material offers outstanding handling and is compatible with all conventional bonding materials.

Special offer 4+1: If you order four packages of Admira Fusion via a VOCO dental consultant, you will receive another package for free. The free goods will be sent to you by VOCO. www.voco.com, call 07500769613.

\title{
Embrace the implant renaissance
}

BioHorizons is delighted to announce that its unmissable one-day event - entitled 'A Contemporary Renaissance Awakening: Aesthetics in Implant Dentistry' - taking place at the Royal College of Physicians in London on Friday 30 September 2016 is now fully booked!

This is an interactive day designed for a revival in thinking on the life-changing impact clinical decisions have on the patient beyond the implant surgery.

As well as exploring the art of achieving aesthetics through the architecture of treatment planning and questioning the importance of material selection to imitate nature, the presentations will consider potential complications, the challenges of case predictability and how to manage patient expectations throughout their personal journey.

Throughout the day the speakers, including Mr James Hamill, Mr Pynadath George, Dr Carlos Repullo Sanchez, Mr Anthony Summerwill, Mr Rob Lynock and Mr Paul Swanson will take delegates on a journey of awakening perceptions on contemporary aesthetics through the latest scientific and innovative clinical evidence within implant dentistry.

For further information, visit www. theimplanthub.com/education or call 01344752560.

\section{A versatile new laser with 25 pre-sets}

Quicklase have recently released the new

Dentalase $5 \mathrm{w}$ laser, an upgrade from the $4 \mathrm{w}$ Dentalase. The $5 \mathrm{w}$ has an $810 \mathrm{~nm}$ wavelength, 20 pre-set menu with the most common soft tissue procedures, including gingivectomy, frenectomy, implant recovery, LLLT and whitening.

The new $5 \mathrm{w}$ soft tissue laser comes complete with all accessories such as whitening and therapy prisms as well as patients' marketing and online training. A 3 metre continuous fibre is used to allow for low maintenance costs, as disposable fibre tips can be expensive. Also, this means there is no need for multiple tips for different procedures, as the fibre can be lengthened for working inside pockets or canals. Another benefit of using a continuous fibre is minimal power loss, as there are fewer connections from the diode to the tip. Quicklase manufacture the $5 \mathrm{w}$ laser in Britain alongside other Dentalase models, $3 \mathrm{w}, 10 \mathrm{w}$ dual and $12 \mathrm{w}$ dual.

Quicklase also sponsor the BILD Academy laser hands-on courses, which run regularly in London with Dr Anoop Maini. Attendees practise over 22 clinical procedures using the Quicklase lasers on sheep head specimens, giving them the confidence to start using a laser straight after the course.

www.quicklase.com.

\section{Providing core CPD in infection control}

\section{Henry Schein Dental understands the} requirement for dental professionals to maintain their CPD in the area of decontamination and infection prevention. As a result, Henry Schein Dental has developed different courses so practices can choose the type of training that suits them best.

- Infection Control Seminars: Regional seminars that qualify for two hours' verifiable CPD and enable practices to look at their existing processes and gain a clearer understanding of the guidelines and what this means for their individual practice

- In-practice infection control: This interactive course is a balance between theory and practical application, tailored and delivered in your own practice to meet your team's specific needs. Choose from one, two or three hour sessions, each attracting verifiable CPD, delivered by infection control specialists at a time and date to suit you

- City \& Guilds-accredited one-day decontamination course: This course is run by infection control specialists Dentisan at their Derby Headquarters. This unique blend of theoretical and hands-on practical learning provides education for the whole dental team and covers every aspect of infection prevention in practices, qualifying for 5.5 hours of verifiable core CPD in infection control. Henry Schein Dental customers qualify for a discount when enrolling on this course. Visit http:// dentisan.co.uk/education/onedaydecon. html for full details of dates, costs and how to book.

hsdeducation.co.uk/call 02072981980. 